\title{
Predation by Misumenops pallidus (Araneae: Thomisidae) on insect pests of soybean cultures in Buenos Aires Province, Argentina
}

Author(s): Alda González, Gerardo Liljesthröm, Elizabet Minervino, Dolores Castro, Sandra González, and Andrea Armendano

Source: Journal of Arachnology, 37(3):282-286. 2009.

Published By: American Arachnological Society

DOI: http://dx.doi.org/10.1636/T08-63.1

URL: http://www.bioone.org/doi/full/10.1636/T08-63.1

BioOne (www.bioone.org) is a nonprofit, online aggregation of core research in the biological, ecological, and environmental sciences. BioOne provides a sustainable online platform for over 170 journals and books published by nonprofit societies, associations, museums, institutions, and presses.

Your use of this PDF, the BioOne Web site, and all posted and associated content indicates your acceptance of BioOne's Terms of Use, available at www.bioone.org/page/terms_of_use.

Usage of BioOne content is strictly limited to personal, educational, and non-commercial use. Commercial inquiries or rights and permissions requests should be directed to the individual publisher as copyright holder. 


\title{
Predation by Misumenops pallidus (Araneae: Thomisidae) on insect pests of soybean cultures in Buenos Aires Province, Argentina
}

\author{
Alda González ${ }^{1}$, Gerardo Liljesthröm ${ }^{1}$, Elizabet Minervino $^{1}$, Dolores Castro ${ }^{2}$, Sandra González $^{1}$ and Andrea Armendano ${ }^{1}$ : ${ }^{1}$ Centro \\ de Estudios Parasitológicos y de Vectores (CEPAVE)(CCT-CONICET-La Plata)(UNLP), 2 N$^{\circ}$ 584, 1900 La Plata, Argentina; \\ ${ }^{2}$ Facultad de Ciencias Naturales y Museo, UNLP. Laboratorio 32 calle $64 \mathrm{~N}^{\circ} 3$ La Plata, Argentina. E-mail: \\ asgonzalez@cepave.edu.ar
}

\begin{abstract}
This study analyzes predation by adult females of Misumenops pallidus (Keyserling 1880) on pairs of prey items representing non-pest insects and potential pests. The phenology of the potential pests was such that each insect guild peaked sequentially, while non-pest herbivorous and insectivorous insects were present during the entire period. Field experiments were made in a commercial 50-ha soybean plot during two successive years. Ten cages $1 \times 1 \times 0.5 \mathrm{~m}$ were placed in peripheral furrows of a soybean commercial plot. The pest species were preyed on differentially, with the order from the most favored species to the least with respect to non-pest herbivorous and insectivorous insects was as follows: defoliating lepidopterous larvae, seed feeding pentatomids in their early nymphal instars, stem boring lepidopterous larvae, and seed feeding pentatomids in older nymphal and adult instars. Adult females of M. pallidus fed on all the insect species offered, but in the presence of defoliator larvae, they hardly accepted alternative prey, whereas in the presence of other prey, they maintained a more generalized diet.
\end{abstract}

Keywords: Agroecosystems, biological control, natural enemies

True predators kill their prey more or less immediately after attacking them, and during their lifetime they will kill several or many different prey individuals. Although most true predators have relatively broad diets, some degree of preference is almost always present (Begon et al. 1996). There is evidence that generalist arthropod predators choose to eat certain prey to balance their amino-acid requirements and therefore may be affected by previous feeding (Greenstone 1979).

While most ecological studies on spiders as potential biocontrol agents in agroecosystems have focused on Lycosidae, Linyphiidae, and Araenidae, much less is known about Thomisidae (Dean et al. 1987; Agnew \& Smith 1989; Lang et al. 1999; Symondson et al. 2002; Vichitbandha \& Wise 2002; Romero \& Vasconcello- Neto 2003; Harwood et al. 2004). In soybean plots in the rolling pampa (Argentina), thomisids represented $47.2 \%$ of all spiders collected in the herbaceous stratum, and Misumenops pallidus (Keyserling 1880) is the most abundant species (Liljesthröm et al. 2002). It is a rather small $(<10 \mathrm{~mm})$ spider that hunts preferentially in the upper and medium strata of the soybean plants. Following the classification proposed by Uetz et al. (1999), it belongs to the guild of hunting ambushers. $M$. pallidus has a relatively long developmental period, and presumably only one generation occurs during the soybean growth period. However, $M$. pallidus exhibits some characteristics of "agrobiont" spiders (Luczak 1979). As a species, it disperses widely, colonizes crops from the beginning of their development, and the adults (particularly females) are found throughout the entire soybean cycle. Apart from this, daily predation rates increase with increasing age of the spider, so that the total number of prey killed by an adult female represents $81 \%$ of prey consumed during its lifetime (Liljesthröm et al. 2002; González et al. 2009).

The most important examples of potential insect prey in soybean fields are represented by three guilds (Root 1967) of primary or secondary pests: intermediate-sized defoliating lepidopterous larvae, stem boring lepidopterous larvae, and seed feeding pentatomids, as well as a complex of other nonpest herbivorous and insectivorous insects (Bimboni 1985; La Porta \& Crouzel 1985; Gamundi 1985; Aragón \& Belloso 1987; Bercellini \& Malacalza 1994; Luna \& Sánchez 1999b). Previous results showed that in the laboratory $M$. pallidus preyed on all prey types except curculionids and adult stink bugs (Cheli et al. 2006). In the present study area, the defoliating guild was represented by Rachiplusia nu Guennée (Lepidoptera: Noctuidae) (Luna \& Sánchez 1999a), the stemboring guild by Crocidosema (=Epinotia) aporema (Walsingham) (Lepidoptera: Tortricidae) (Luna et al. 1996; Liljesthröm \& Rojas 2005), and the seed-feeding stink bugs by Nezara viridula (Linnaeus) and Piezodorus guildinii West. (Hemiptera: Pentatomidae) as the most abundant species (Bimboni 1985; Bercellini \& Malacalza 1994; Liljesthröm \& Coviella 1999; Frana 2008). Among non-pest herbivorous and insectivorous insects, the following were the most abundant: Colaspis sp. and Diabrotica speciosa (Germ.) (Coleoptera: Chrysomelidae), Eriopis conexa (Germ.), Cycloneda sanguinea (Germ.), Coccinella sp. (Coleoptera: Coccinelidae), unidentified species of Membracidae and Cicadellidae (Homoptera: Auchenorrhynca), and a species of Curculionidae (Aragón \& Belloso 1987; Bercellini \& Malacalza 1994).

Although non-pest insects were recorded during the entire soybean growth period with only small variations in density, the phenology of the potential pests is such that each guild peaks sequentially. $R$. nu larvae peaked during the early vegetative stages of soybean growth (V4-V6) in late January during two consecutive years, mean peak density was 17.6 larvae/ linear meter; stem-boring larvae peaked in numbers (9.1 individuals/ linear meter) during later vegetative stages (V7-V8) in mid February. The small instars of seed feeders peaked during reproductive stages (R3-R6) in mid March (mean peak density was 11.2 larvae/ linear meter) and large 
instars peaked 2-3 wk later at a lower density (Aragón \& Belloso 1987; Bercellini \& Malacalza 1994; González et al. in press).

In this work, we analyze daily predation by adult female $M$. pallidus on pairs of different prey types, each pair consisting of one pest and one non-pest species. We hypothesized that $M$. pallidus would prey indistinctly on all prey except adult curculionids (a component of non-pest insects in some treatments) and adult stink bugs, and that they would exhibit similar preferences toward all pairs of prey types offered, excluding the former.

\section{METHODS}

Predation by adult female M. pallidus was estimated in four field experiments conducted in a commercial 50-ha soybean plot located in Chivilcoy $\left(34^{\circ} 54^{\prime} \mathrm{S}, 60^{\circ} 02^{\prime} \mathrm{W}\right)$, Buenos Aires province, during two successive years. The area belongs to the pampean phytogeographic province (Cabrera 1976). The climate is humid-mesothermal, and apart from cattle, the main agricultural products are soybean, maize, and wheat.

Two kinds of potential prey (a pest and a non-pest species) were offered in each of four experiments that were repeated in both years, and the density of potential prey (4 per cage) represented approximately the mean pest density (expressed as the number of individuals per linear meter of crop) during the entire phenological soybean period in the field (González et al. 2009). In each experiment, we used 10 cages, $1 \times 1 \times 0.5 \mathrm{~m}$, covered with a nylon net $(1 \times 1 \mathrm{~mm})$. The cages were placed in peripheral furrows of a commercial soybean plot. The area where each cage would be placed was first cleared by hand. All litter, soybean plants, weeds, and insects were eliminated, and the bare ground flattened and compacted. Then we placed three plastic pots containing soybean plants in a phenological state similar to those of the crop and covered them with the cage (which was sunk into the soil to prevent the entrance of ground-active arthropods). We placed potential prey individuals in each cage, as follows:

1) Two $R . n u\left(3^{\text {rd }}-4^{\text {th }}\right.$ larval instars; defoliators $)$ and two non-pest insects (D. speciosa and Coccinella sp. in the first year, and D. speciosa and Colaspis sp. in the second year). The experiment was carried out in late January when defoliating lepidopterous larvae peaked.

2) Two $C$. aporema $\left(4^{\text {th }}-5^{\text {th }}\right.$ larval instars, which were placed on a leaf near a bud. It was expected that each larva would protect itself by stitching together silk threads or boring a stem before a spider and two nonpest insects ( $D$. speciosa and a membracid in the first year and $D$. speciosa and an unidentified curculionid in the second year) were released into the cage. The experiment was carried out in mid-February when stem-boring lepidopterous larvae peaked.

3) Two N. viridula ( $3^{\text {rd }}$ instar nymphs, seed-feeding) and two non-pest insects (D. speciosa and a membracid in the first year and only $D$. speciosa in the second year). The experiment was carried out in mid-March when seed-feeding pentatomid nymphal instars peaked.
4) Two $N$. viridula ( $5^{\text {th }}$ instar nymphs) and adult $P$. guildinii (both seed-feeders) and two non-pest insects (Coccinella sp., which preyed mainly on aphids and Thysanoptera, and D. speciosa in the first year and only $D$. speciosa in the second year). The experiment was carried out in late March, when adult stink bugs usually exhibit maximum density.

The prey species and adult spiders used in the experiments were collected in the field with a $40-\mathrm{cm}$ diameter sweeping net. The specimens were deposited in the Arachnological Laboratory of the Center of Parasitological Studies (University of La Plata) at the study's conclusion. The potential prey were placed in the 10 cages (grouped in pairs of a pest and a nonpest species) at the beginning of the experiments and left for 24 hours to allow acclimation. Adult female spiders were collected in the field three to four days before, and after a 48hour fasting period were provided with an adult Drosophila melanogaster for standardization of hunger level. Then one spider was introduced into each of five cages selected at random, while the remaining five cages were spider-free controls. Prey and predators were kept together for 24 hours; then we disassembled the cages and counted the number of individuals remaining.

For each of the four combinations of prey items and for both years, we analyzed predation by adult female $M$. pallidus by calculating the predation rate per cage (Kajak et al. 1968). We calculated the daily predation rate per cage on the i-th prey type, $\operatorname{DPR}(i)$, as:

$$
\operatorname{DPR}(i)=[\mathrm{No}(i)-\mathrm{Nf}(i)-\mathrm{Ns}(i)] / \mathrm{No}(i) / \Delta \mathrm{t}
$$

where $\mathrm{No}(i)$ and $\mathrm{Nf}(i)$ represent, respectively, the initial and final number of the i-th prey type in the cage with spiders, $\mathrm{Ns}(i)$ the mean number of missing $\mathrm{i}$-th prey type in the control cages, and $\Delta \mathrm{t}=1$ day, the duration of the experiment. Each year, possible differences between treatments were analyzed by MANOVA, and in each treatment DPR $(i)$ values corresponding to the $i$-th insect pest and non-pest insects in each experiment was examined with a $t$-test. We also calculated the total number of all prey types preyed on per cage per day:

$$
\begin{aligned}
\mathrm{DPR}= & {[\mathrm{No}(i)-\mathrm{Nf}(i)-\mathrm{Ns}(i)] } \\
& +[\mathrm{No}(N P I)-\mathrm{Nf}(N P I)-\mathrm{Ns}(N P I)]
\end{aligned}
$$

Differences among treatments in both years (prey killed per cage) were tested by ANOVA, and homogeneity of variances was tested by Levene's test. No transformation was necessary.

\section{RESULTS}

We recorded the disappearance of only one insect from the control cages: a $R$. nu in the second year. In the treatment cages $M$. pallidus caught prey of all those offered except the adult curculionid and $P$. guildinii. However, the predation rates showed that some pests were preferred over non-pest insects, while others were less preferable. The same tendency was observed both years: $F_{3} .30=7.154 ; P=0.00008$ (first year), and $F_{3.30}=3.997 ; P=0.0047$ (second year) (Figs. 1a, b).

When we analyzed each treatment separately, the defoliating lepidopterous larvae exhibited a higher predation rate than 

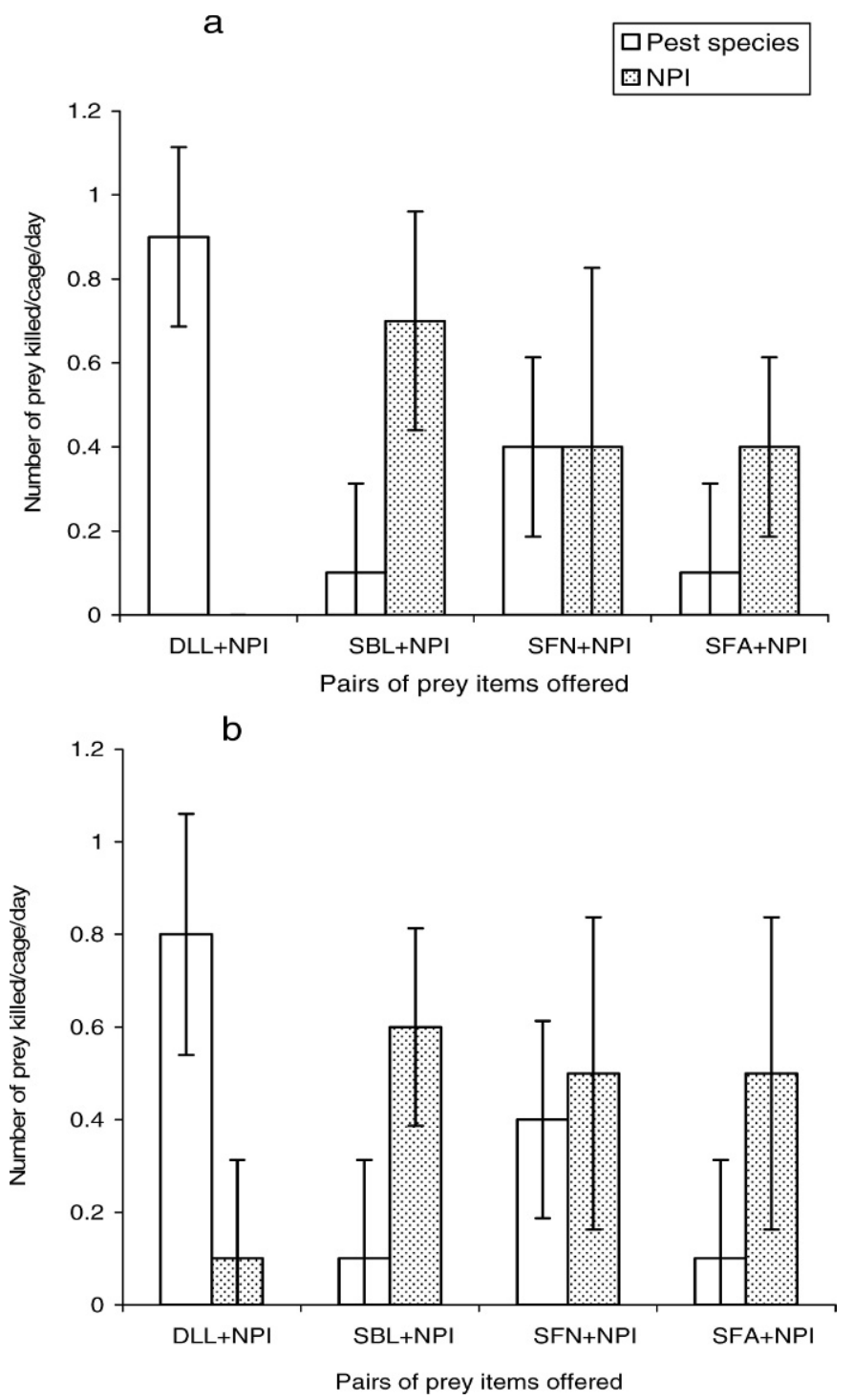

Figure 1a, b.-Predation rate of an adult female Misumenops pallidus when a pest species and non-pest insects were offered. a. During the first year of studies; b. During the second year of studies. $(\mathrm{DLL}=$ defoliator lepidopterous larvae, $\mathrm{SBL}=$ stem borer lepidopterous larvae, SFN = seed feeding pentatomids in the first three nymphal instars, SFA = seed feeding pentatomids in older nymphal instars and in the adult stage NPI $=$ non-pest herbivorous and insectivorous insects). Confidence intervals at $90 \%$ probability.

non-pest insects. Conversely, in both years the stem-boring lepidopterous larvae were preyed on less than the non-pest insects. In both years the predation rate on stink bugs did not differ statistically from that of non-pest insects. In the first three nymphal instars, the predation rate on the bugs was similar to that of non-pest insects. When bugs were later instar nymphs or in the adult stage, the predation rate on later-stage nymphs and adults was lower than that on non-pest insects, but not significantly so. In the latter case, only late-instar nymphs, but not adults, were preyed on.

For the total number of prey killed daily per cage, the daily predation rates varied from 1 to 1.8 in the first year, but differences were not significant $\left(F_{3.16}=1.85, P<0.18\right)$. In the second year, minimum and maximum daily predation rates were 1.2 and 1.8 , respectively, and non-significant $\left(F_{3.16}=\right.$ $1.02, P<0.41)$. Thus, regardless of the prey types offered, the spiders killed approximately the same number of prey items.

\section{DISCUSSION}

Adult female $M$. pallidus killed one to almost two prey items per cage per day and fed on all the offered insect species except adult stink bugs and adult curculionids. These values are congruent with field estimates by Edgar (1969) and Nyffeler \& Benz (1987, 1988); however, prey densities could be different in those situations. $M$. pallidus acted almost as a specialist predator in the presence of the defoliating $R . n u$, whereas in the presence of other prey guilds, it showed a more varied feeding pattern. Yet the low attack rate of the spider on the stem $\mathrm{s}$ is likely due to a low encounter rate with this prey guild, similar to small defoliating larvae. The stem-boring larvae remain hidden from potential predators inside cocoons made of leaves stitched together with silk threads. However, they are parasitized by larval parasitoids (Liljesthröm \& Rojas 2005). Other species of herbivores that spend a large proportion of their life cycles in cryptic locations are not susceptible to significant predation by carabids, staphylinids, and spiders but are susceptible to specialist natural enemies (Rämert \& Ekbom 1996). On the other hand, the low attack rate on stink bugs is likely due to a certain degree of invulnerability of this prey guild, particularly adults because of their relatively large size, their thick cuticle, and production of toxic compounds (Aldrich 1988; Staddon 1979; Pareja et al. 2007). These factors probably explain why most of the predation on this guild was on fifth-instar nymphs (mainly by $N$. viridula, which is larger than $P$. guildinii); we only saw nymphs preyed on by adult spiders in the field. The thickness of the adult curculionid cuticles could also account for our results.

Studies by Turnbull (1960) and Riechert \& Lockley (1984) demonstrated prey size selectivity in spiders, and Nentwig (1983) showed that most of his web-building spiders caught and ate almost anything small enough for them to handle that arrived in their webs, although they rejected prey that was toxic or whose cuticule was too hard to penetrate.

Spiders are the main natural enemies of pest insects in some agroecosystems, which makes them agronomically significant (Riechert \& Lockley 1984). Notwithstanding, early biological control studies focused on specialist predators rather than on spiders because, as generalists, they were thought to have relatively little impact on agricultural pests (Savory 1928; Bristowe 1941; Comstock 1965). This view has changed, and different studies have demonstrated the capacity of spiders to reduce the population density of some pest insects and their consequent damage (Riechert \& Lockley 1984; Nyffeler et al. 1992; Riechert \& Lawrence 1997; Marshall et al. 2002). Still, other studies indicate limited pest control potential under certain conditions (Holland \& Thomas 1997; Lang et al. 1999; Birkhofer et al. 2008). On the other hand, since effective biological control is the result of complex interactions at the community level, the activity of spiders would be complemented by that of other natural enemies (Sunderland 1999), although it was observed in the field that M. pallidus preyed on the taquinid Trichopoda giacomellii (Blanchard), a parasitoid of $N$. viridula (Liljesthröm, pers. obs.), and coccinelid predators (this study). 
Polyphagy helps to sustain predators when pest density is low in agroecosystems, usually early in the season. Generalists may already be present, subsisting on non-pest prey, while specialist parasitoids may take some time to build up in numbers (Symondson et al. 2002). In soybean cultures in the study area, defoliating and stem-boring larvae have different guilds of parasitoids (Luna \& Sánchez 1999a; Liljesthröm \& Rojas 2005), while late-instar nymphs and adults of $N$. viridula are attacked by T. giacomellii (Liljesthröm \& Bernstein 1990; Liljesthröm \& Rabinovich 2004). Yet the only arthropod natural enemies found on young-instar nymphs of $N$. viridula, as well as on adults and immature stages of $P$. guildinii, are predators, among which spiders are the most abundant (Bercellini \& Malacalza 1994; Liljesthröm et al. 2002). We found many other spider species representing seven guilds that reached relatively high densities (Liljesthröm et al. 2002) and could prey on certain potential pest species. Even though their effect is unknown in the agroecosystem, they are important mortality factors on the pest species considered in this study, as well as on other phytophagous insects that rarely attain pest status.

\section{ACKNOWLEDGMENTS}

We are grateful to two anonymous referees for helpful suggestions on previous versions of this manuscript.

\section{LITERATURE CITED}

Aldrich, J.R. 1988. Chemical ecology of the Heteroptera. Annual Review of Entomology 33:211-238.

Aragón, J.R. \& C.A. Belloso. 1987. Control de plagas. In: Producción de soja. Cuaderno de Actualización Técnica $\mathrm{N}^{\circ}$ 58. Asociación Argentina de Consorcios Regionales de Experimentación Agrícola, Buenos Aires, Argentina.

Agnew, C.W. \& J.W. Smith. 1989. Ecology of spiders (Araneae) in a peanut agroecosystem. Environmental Entomology 18:30-42.

Begon, M., M. Mortimer \& D.J. Thompson. 1996. Population Ecology: A Unified Study of Plants and Animals. 3rd Edition. Wiley-Blackwell Science, Oxford, UK.

Bercellini, N. \& L. Malacalza. 1994. Plagas y depredadores en soja en el noroeste de la provincia de Buenos Aires (Argentina). Turrialba 44:244-254.

Bimboni, M.A. 1985. Plagas de la soja. Estación Experimental Agropecuaria San Pedro, Instituto Nacional de Tecnología Agropecuaria, Buenos Aires, Argentina.

Birkhofer, K., A. Fliessbach, D.H. Wise \& S. Scheu. 2008. Generalist predators in organically and conventionally managed grass-clover fields: implications for conservation biological control. Annals of Applied Biology 153:271-280.

Bristowe, W.S. 1941. The Comity of Spiders. Volume II. The Ray Society, London.

Cabrera, A.L. 1976. Regiones Fitogeográficas Argentinas. Enciclopedia Argentina de Agricultura y Jardinería. Tomo II, Fascículo 1. Editorial Acme S.A.C.I., Buenos Aires, Argentina.

Comstock, J.H. 1965. The Spider Book. Comstock Publishing, Ithaca, New York.

Cheli, G., A. Armendano \& A. González. 2006. Preferencia alimentaria de arañas Misumenops pallidus (Araneae: Thomisidae) sobre potenciales insectos presa de cultivos de alfalfa. Journal of Tropical Biology 54:505-513.

Dean, D.A., W.L. Sterling, M. Nyffeler \& R.G. Breene. 1987. Foraging by selected spider predators on the cotton fleahopper (Hemiptera, Miridae) and other prey. Southwestern Entomologist 12:263-270.
Edgar, W.D. 1969. Prey and predators of the wolf spider Lycosa lugubris (Walckenaer). Journal of Zoology 159:405-411.

Frana, J.E. 2008. Tendencias de abundancia de chinches en soja en el centro de Santa Fe. Pp. 21-30. In Chinches fitófagas en soja. Revisión y avances en el estudio de su ecología y manejo. (E.V. Trumper \& J.D. Edelstein, eds.). Estación Experimental Agropecuaria, Instituto Nacional de Tecnología Agropecuaria, Manfredi, Buenos Aires, Argentina.

Gamundi, J.C. 1985. Control integrado de insectos plaga en el cultivo de soja. In: Actas de Jornadas de Actualización Profesional Sobre Cultivos de Cosecha Gruesa., Instituto Nacional de Tecnología Agropecuaria, Buenos Aires Argentina.

González, A., G. Liljesthröm, D. Castro \& A. Armendano. 2009. Development and recruitment of Misumenops pallidus (Keyserling) (Araneae: Thomisidae), and its synchrony with three potential prey species in soybean cultures from Argentina. Entomological News 120:41-53.

Greenstone, M.H. 1979. Spider feeding behaviour optimises dietary essential amino acid composition. Nature 282:501-503.

Harwood, J.D., K.D. Sunderland \& W.O.C. Symondson. 2004. Prey selection by linyphiid spiders: molecular tracking of the effects of alternative prey on rates of aphid consumption in the field. Molecular Ecology 13:3549-3560.

Holland, M. \& S.R. Thomas. 1997. Quantifying the impact of olyphagous invertebrate predators in controlling cereal aphids in preventing wheat yield and quality reductions. Annals of Applied Biology 131:375-397.

Kajak, A., L. Andrzejewska \& Z. Wojcik. 1968. The role of spiders in the decrease of damages caused by Acridoidea on meadows. Experimental investigation. Ekologia Polska 16:756-764.

Lang, A., J. Filser \& J.R. Henschel. 1999. Predation by ground beetles and wolf spiders on herbivorous insects in a maize crop. Agriculture, Ecosystems and Environment 72:189-199.

La Porta, N.C. \& I.S. Crouzel. 1985. Estudios básicos para el control biológico de Nezara viridula (L., 1758) (Hemiptera: Pentatomidae) en la Argentina. Revista de la Sociedad Entomológica Argentina 43:119-143.

Liljesthröm, G. \& C. Bernstein. 1990. Density dependence and regulation in the system Nezara viridula (L.) (Hemiptera: Pentatomidae), host and Trichopoda giacomellii (Blanchard) (Diptera: Tachinidae), parasitoid. Oecologia 84:45-52.

Liljesthröm, G. \& C. Coviella. 1999. Aspectos de la dinámica poblacional de las chinches Nezara viridula y Piezodorus guildinii e implicancias con relación a su manejo en el cultivo de soja. Revista de la Sociedad Entomológica Argentina 58:141-149.

Liljesthröm, G., E. Minervino, D. Castro \& A. González. 2002. La comunidad de arañas del cultivo de soja en la provincia de Buenos Aires, Argentina. Neotropical Entomology 31:197-209.

Liljesthröm, G. \& J. Rabinovich. 2004. Modeling biological control: the population regulation of Nezara viridula by Trichopoda giacomellii. Ecological Applications 14:254-267.

Liljesthröm, G. \& G. Rojas. 2005. Parasitismo larval de Crocidosema (=Epinotia) aporema (Lepidoptera: Tortricidae) en el noreste de la provincia de Buenos Aires (Argentina). Revista de la Sociedad Entomológica Argentina 64:37-44.

Luczak, J. 1979. Spiders in agrocoenoses. Polish Ecological Studies 5:151-200.

Luna, M.G., E. Minervino \& N. Buselini. 1996. Diagnóstico sobre el manejo de plagas en el cultivo de soja en el partido de Chivilcoy, Buenos Aires, Argentina. Revista de Agronomía de La Plata 101:1-6.

Luna, M.G. \& N.E. Sánchez. 1999a. Composición específica y abundancia de la comunidad de lepidópteros defoliadores de la soja en el noroeste de Buenos Aires, Argentina. Revista de la Sociedad Entomológica Argentina 58:67-75.

Luna, M.G. \& N.E. Sánchez. 1999b. Parasitoid assemblages of soybean defoliator Lepidoptera in north-western Buenos Aires 
province, Argentina. Agricultural and Forest Entomology $1: 255-260$.

Marshall, S.D., D.M. Pavuk \& A.L. Rypstra. 2002. A comparative study of phenology and daily activity patterns in the wolf spiders Pardosa milvina and Hogna helluo in soybean agroecosystems in southwestern Ohio (Araneae, Lycosidae). Journal of Arachnology 30:503-510.

Nentwig, W. 1983. The prey of web-building spiders compared with feeding experiments (Araneae: Araneidae, Linyphiidae, Pholcidae, Agelenidae). Oecologia 56:132-139.

Nyffeler, M. \& G. Benz. 1987. Spiders in natural pest control: a review. Journal of Applied Entomology 103:321-339.

Nyffeler, M. \& G. Benz. 1988. Feeding ecology and predatory importance of wolf spiders (Pardosa spp.) (Araneae, Lycosidae) in winter wheat fields. Journal of Applied Entomology 106:123-134.

Nyffeler, M., D.A. Dean \& L. Sterling. 1992. Diets, feeding specialization, and predatory role of two lynx spiders, Oxyopes salticus and Peucetia viridans (Araneae, Oxyopidae) in Texas cotton agroecosystem. Environmental Entomology 21:1457-1465.

Pareja, M., M. Borges, R.A. Laumann \& M.C.B. Moraes. 2007. Inter- and intraspecific variation in defensive compounds produced by five neotropical stink bug species (Hemiptera: Pentatomidae). Journal of Insect Physiology 53:639-648.

Rämert, B. \& B. Ekbom. 1996. Intercropping as a management strategy against carrot rust fly (Diptera: Psilidae): a test of enemies and resource concentration hypotheses. Environmental Entomology 25:1092-1100.

Riechert, S.E. \& T. Lockley. 1984. Spiders as biological control agents. Annual Review of Entomology 29:299-320.
Riechert, S.E. \& K. Lawrence. 1997. Test for predation effects of single versus multiple species of generalist predators: spiders and their insect prey. Entomologia Experimentalis et Applicata 84:147-155.

Romero, G.Q. \& J. Vasconello-Neto. 2003. Natural history of Misumenops argenteus (Thomisidae): seasonality and diet on Trichogoniopsis adenantha (Asteraceae). Journal of Arachnology 31:297-304.

Root, R.B. 1967. The niche exploitation pattern of the blue-gray gnatcatcher. Ecological Monographs 37:317-350.

Savory, T.H. 1928. The Biology of Spiders. Macmillan Co., New York.

Staddon, B.W. 1979. The scent glands of Heteroptera. Advances in Insect Physiology 14:351-419.

Sunderland, K. 1999. Mechanisms underlying the effects of spiders on pest populations. Journal of Arachnology 27:308-316.

Symondson, W.O.C., K.D. Sunderland \& M.H. Greenstone. 2002. Can generalist predators be effective biocontrol agents? Annual Review of Entomology 47:561-594.

Turnbull, A.L. 1960. The prey of the spider Linyphia triangularis (Clerck) (Araneae, Linyphiidae). Canadian Journal of Zoology 38:859-873.

Uetz, G.W., J. Halaj \& A.B. Cady. 1999. Guild structure of spiders in major crops. Journal of Arachnology 27:270-280.

Vichitbandha, P. \& D.H. Wise. 2002. A field experiment on the effectiveness of spiders and carabid beetles as biocontrol agents in soybean. Agricultural and Forest Entomology 4:31-38.

Manuscript received 23 July 2008, revised 5 May 2009. 